\title{
Testicular adrenal rest tumors in children with congenital adrenal hyperplasia
}

Waad M. Al-Ghamdi, SPB, Mohamed A. Shazly, MSc, Abdulmoein E. Al-Agha, FRCPCH.

\begin{abstract}

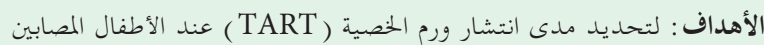

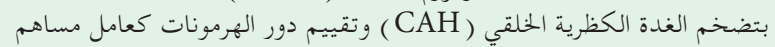

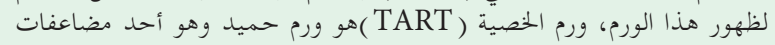

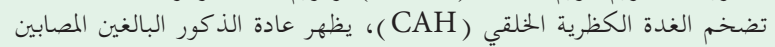
حيث بلغ انتشاره ب0\% (CAH)

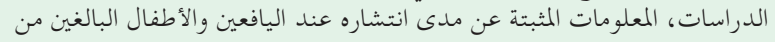

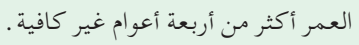

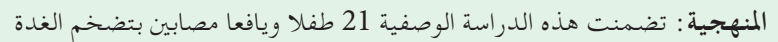

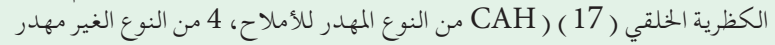

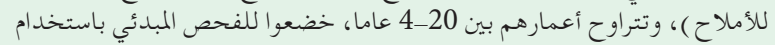

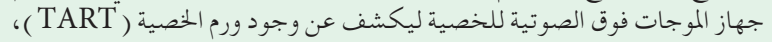

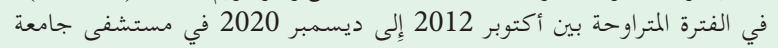

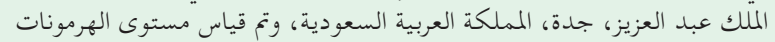
أبطاٍ

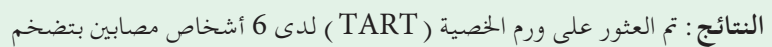

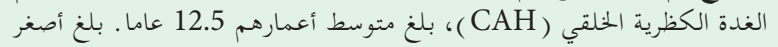

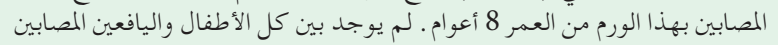

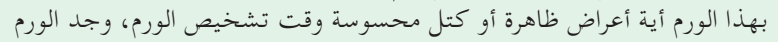

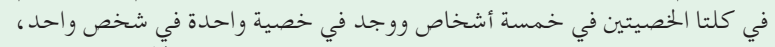

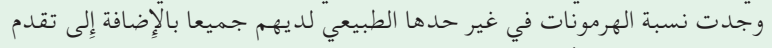
العمر العظمي لدى 4 من المصابين.

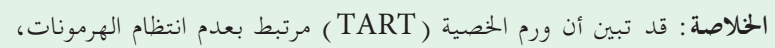

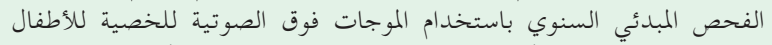

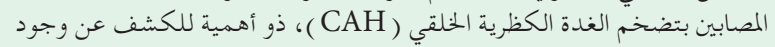

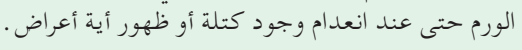

Objectives: To identify testicular adrenal rest tumors (TARTs) prevalence among children with congenital adrenal hyperplasia (CAH) and to assess hormonal control role as a contributing factor for TART development. Testicular adrenal rest tumors are benign tumors complicating $\mathrm{CAH}$. It affects adult males with CAH commonly, with a reported prevalence of $40 \%$ on average, and up to $94 \%$. There is insufficient data regarding their prevalence in children aged above 4 years and adolescents.
Methods: This descriptive study included 21 children and adolescents with CAH (17 salt wasting type, 4 non salt wasting type) aged 4-20 years who were screened for TARTs by routine testicular ultrasonography from October 2012 to December 2020 at King Abdulaziz University Hospital, Jeddah, Kingdom of Saudi Arabia. Serum adrenocorticotropic hormone, 17-hydroxy progesterone, testosterone, dehydroepiandrosterone, and luteinizing hormone levels were measured.

Results: Testicular adrenal rest tumors were detected in $6(28 \%)$ patients (median age: 12.5 years). The youngest affected child was 8 years old. All patients with TARTs were asymptomatic with impalpable testicular masses at the time of detection. Bilateral involvement was observed in 5 patients, while one patient had unilateral involvement. All patients with TARTs had poor hormonal control, and 4 patients had advanced bone age.

Conclusion: Testicular adrenal rest tumors development has been shown to correlate with poor hormonal control. Annual screening of young children with CAH for TART development is crucial, even for asymptomatic or with impalpable testicular masses.

Keywords: testicular adrenal rest tumors, congenital adrenal hyperplasia, children, prevalence, hormonal control.

Saudi Med J 2021; Vol. 42 (9): 986-993 doi: 10.15537/smj.2021.42.9.20210257

From the Department of Pediatric, Faculty of Medicine, King Abdulaziz University Hospital, Jeddah, Kingdom of Saudi Arabia.

Received 1st April 2021. Accepted 7th July 2021.

Address correspondence and reprint request to: Prof. Abdulmoein E. Al-Agha, Pediatric Department, Faculty of Medicine, King Abdulaziz University, Jeddah, Kingdom of Saudi Arabia. E-mail: aagha@kau.edu.sa

ORCID ID: https://orcid.org/0000-0002-7168-6447 
C ongenital adrenal hyperplasia $(\mathrm{CAH})$ is a group of autosomal recessive disorders affecting the adrenal gland, characterized by a genetic mutation involved in steroidogenic enzyme production. Congenital adrenal hyperplasia is observed in early childhood with an incidence ranging from 5000 to 15,000, its prevalence in the Kingdom of Saudi Arabia (KSA) is not known so far; however, an estimated incidence between 4000 and 3500 has been reported. ${ }^{1,2}$

Patients with $\mathrm{CAH}$ including young children are at risk of developing testicular adrenal rest tumor (TART) as a common complication. Where many reports diagnosed TARTs in children with $\mathrm{CAH}$ as young as 4-7.5 years. ${ }^{3-7}$ Testicular adrenal rest tumor was not detected in infants and toddlers; however, a single study reported the youngest affected patient at the age of 1.8 years. ${ }^{8,9}$ The prevalence of TART in adult patients with $\mathrm{CAH}$ is up to $94 \%{ }^{10}$

Testicular adrenal rest tumor is a benign tumor originating from adrenal cells within the testicles; at 8 weeks of gestation, these cells migrate from the urogenital ridge along with the gonadal cells to the testicle. The exact mechanism underlying tumor growth and development is still not well understood.

Testicular adrenal rest tumor affects the testes bilaterally in more than $80 \%$ of cases. Most children are asymptomatic with no palpable mass, and the mass is considered palpable when it reaches $\geq 2 \mathrm{~cm}$ in size due to its presence in the rete testes near the mediastinum. ${ }^{11}$ Subsequently, early ultrasound screening is recommended every $1-2$ years. ${ }^{3,6}$

This study aimed to identify the prevalence of TARTs in children with CAH who were living in KSA, and to assess poor hormonal control and medication adherence as contributing factors for TART occurrence.

Methods. This retrospective study included 21 male children and adolescents with all types of CAH (17 salt wasting type, 4 non salt wasting type) aged from 4-20 years. They were followed in the endocrinology outpatient clinic from October 2012 to December 2020 at King Abdulaziz University Hospital (KAUH), Jeddah, KSA. Exclusion criteria included male patients with CAH below the age of 4 years or older than 20 years, and those who were lost to follow-up or with insufficient data in their medical records.

Disclosure. Authors have no conflict of interests, and the work was not supported or funded by any drug company.
All patients with $\mathrm{CAH}$ were diagnosed based on clinical and laboratory manifestations. Clinical examinations were performed on all patients with TARTs to detect the presence of any palpable testicular masses by an experienced endocrinologist. Moreover, assessment of hyperandrogenism, characterized by excessive hair growth on the body or face, scalp baldness, inflamed skin with acne, and increased body pigmentation, was performed.

Anthropometric measurements. The height and weight of all patients were measured in centimeters and kilograms, in the outpatient clinic screening unit. Body mass index (BMI) was calculated using the quetelet's index: body weight in kilograms divided by height in meters squared. ${ }^{12}$

Evaluation of testicular volume and Tanner staging. Patients with TART were evaluated for testicular volume using an orchidometer, and penile lengths were measured in centimeters and plotted on a penile growth chart, while pubertal assessments using Tanner staging were conducted to evaluate the presence of external sexual characteristics, including genital size and distribution of pubic hair, in the following 5 stages:

Stage I: testes size $<4 \mathrm{ml}$ in volume and $<2.5 \mathrm{~cm}$ in longest diameter, thinning of the scrotum, and no pubic hair. Stage II: testes size of $4-8 \mathrm{~mL}$ in volume and $2.5-3.3 \mathrm{~cm}$ in longest diameter, scrotal skin redness and change in texture, and few straight, light in color and without curls pubic hairs, around the penis. Stage III: enlargement of the penis with further growth of the testes $(9-12 \mathrm{~mL}$ in volume and $3.4-4 \mathrm{~cm}$ in longest diameter), and darker and curlier pubic hair mostly located at the penis root. Stage IV: an increase in penis size, further growth of the testes $(15-20 \mathrm{~mL}$ in volume and $4.1-4.5 \mathrm{~cm}$ in longest diameter), increase in shoulder breadth, darkening of the scrotal skin, and darker, curlier, and denser pubic hair reaching the inner thighs. Stage V: adult genitalia, testes size $>20 \mathrm{~mL}$ in volume and $>4.5 \mathrm{~cm}$ in longest diameter, pubic hair extending to the umbilicus. ${ }^{13-15}$

Radiological evidence. All patients with CAH above the age of 4 years underwent testicular ultrasound screening by a pediatric radiologist using the L12-5 linear transducer (Philip Epiq 7G Ultrasound machine with Doppler). Electronic reports of the sonographic data described the tumor size, site, borders, echogenicity, and vascularity. Annual sonographic follow-up examinations were performed on all children with $\mathrm{CAH}$ to diagnose new patients for the presence of TARTs and monitor those with an existing tumor for the mass size in correspondence to treatment.

Bone age was assessed using a radiograph of the non-dominant hand and wrist for patients with $\mathrm{CAH}$, 
TARTs, and subsequently correlated with age using the Greulich and Pyle atlas. ${ }^{16}$

Staging of TART. Very small lesions consisting of adrenal rest cells within rete testis found in stage one cannot be detected by scrotal ultrasound, while in stage 2, the proliferation of these cells occurs with possible detection by ultrasound. In stage 3, they infiltrate and compress the parenchyma, obstructing the seminephrous tubules along with a hormonal disturbance affecting the gonads. In stage 4, they increased in number and size with lymphocytic infiltration and fibrosis, eventually resulting in progressive obstruction and chronic destruction to the testicular tissue leading to irreversible damage in stage $5 .{ }^{11}$

Hormonal assays. Data of all patients with TARTs was collected retrospectively. Hormonal assays were conducted every 3-6 months during follow up. Adrenocorticotropic hormone (ACTH) levels were analyzed with electrochemiluminescence immunoassay (ECLIA) using a Cobas Elecsys 2010 (Cobas Elecsys 2010, Roche, Mannheim, Germany), 17-hydroxy progesterone (17-OHP) level was determined using an enzyme immunoassay, while testosterone, dehydroepiandrosterone (DHEA-S), and luteinizing hormone (LH) levels were measured with a Metallica IM analyzer using direct chemiluminescent (SIEMENS Healthineers). Data was collected from the electronic medical records, and hormone levels were interpreted according to the patient's age as follows: age dependent normal reference ranges of hormones in males based on local center reference in KAUH, Jeddah, KSA, laboratory: ACTH in pmol/L: 1 week to 9 years: $1.1-10.12 ; 10$ to 18 years; $1.32-12.1,19$ years or older; $1.54-15.18$. 17-OHP in ng/mL: $5-9$ years: $\leq 0.9 ; 10$ to 13 years: $\leq 1.69$; $14-17$ years: $0.16-2.83$. Dehydroepiandrosterone sulfate (DHEAS) in umol/L: 4-6 years: $\leq 0.729$; 7-9 years: $\leq 2.457$; $10-13$ years: $\leq 3.726$; $14-17$ years: 1.026-9.218. Total serum testosterone in $\mathrm{nmol} / \mathrm{L}: 1-5.9$ years: $\leq 0.17$; $6-7.9$ years: $\leq 0.85 ; 8-10.9$ years: $\leq 1.43$; $11-11.9$ years: $\leq 8.84 ; 12-13.9$ years: $\leq 14.28 ; 14-17.9$ years: $\leq 34.67$; 18 years or more: $8.5-37.4$. LH in IU/L: 3-7 years: $<0.26$; $8-9$ years: $<0.46$; $10-11$ years: $<3.13$; $12-14$ years: $0.23-4.41 ; 15-17$ years: $0.29-4.77$.

Management of children with CAH. In this study, all patients with $\mathrm{CAH}$ were prescribed hydrocortisone $\left(12-18.7 \mathrm{mg} / \mathrm{m}^{2} /\right.$ day divided into 3 doses), while fludrocortisone $(0.05-0.2 \mathrm{mg} / \mathrm{day})$ was added for patients with $\mathrm{CAH}$ salt losing type.

Routine follow-up of patients with $\mathrm{CAH}$ was carried out every 3-months with clinical, laboratory, and radiological evaluations with hydrocortisone dose adjustment according to their evaluations.
In patients who developed TARTs (stages 1, 2 and 3) due to poor hormonal control, hydrocortisone doses were increased up to $20 \mathrm{mg} / \mathrm{m}^{2} /$ day or substituted with the equivalent dexamethasone doses to shrink or suppresses further tumor growth. In contrast, those who developed stages 4 and 5 TARTs were referred for surgical evaluations.

Ethical consideration. The institutional review board of King Abdulaziz University Hospital provided ethical approval prior to study implementation. Informed consent was obtained from all participants (from either the patients or their parents). The confidentiality of patient data was maintained according to the Declaration of Helsinki. Reviewing related articles was conducted using Google Scholar and PubMed databases.

Statistical analysis. Data was entered and statistically analyzed using the Statistical Package for Social Sciences (SPSS) software version 20.0 (IBM Corp, Armonk, NY, USA). ${ }^{17}$ Regression analysis was performed to assess any correlation between hormonal control and TART development in patients with $\mathrm{CAH}$, and confidence intervals (CIs) and $p$-values were calculated. A $p$-value of $<0.05$ was considered significant.

Shapiro wilk test was used to evaluate the normal distribution of continuous data, which were presented as mean and standard deviation or median and interquartile range according to data distribution. In contrast, qualitative variables are expressed as frequency and percentage. Student t-test and Mann-Whitney test were used to compare continuous variables between the 2 study groups according to data distribution. Multiple logistic regression was performed to study independent factors affecting TART development.

Results. Twenty-one male children diagnosed with CAH between the age of 4-20 years, (median age: 11 years) were screened routinely with scrotal ultrasonography.

Testicular adrenal rest tumors were detected in 6 patients $(28 \%)$ at the age of $8-20$ years either at the initial screening or during the annual follow-up. The median age of TART detection was 12.5 years. The youngest patient diagnosed with TARTs was 8 years old. Four patients with TARTs were $\leq 15$ years at the time of diagnosis (67\%), while only 2 patients were above the age of 15 years.

Only one patient was found to have a palpable nodular testicular mass during clinical examinations. The BMI of patients with TARTs ranged from 20-32 kg/m² (median: $25 \mathrm{~kg} / \mathrm{m}^{2}$ ). Further details of the patient's clinical characteristics are summarized in Table 1. 
Tanner staging and testicular volume. Three patients with TARTs had Tanner staging between IV-V. Five males had penile length measurements higher than the upper limits for their age when plotted on penile growth charts, and the measurement was within the normal limit in one male, indicating poor control of hyperandrogenic hormones. Tanner staging, testicular volume, and penile length measurements of patients with TARTs are summarized in Table 1.

Radiological investigations. All children with $\mathrm{CAH}$ above the age of 4 years were screened with testicular ultrasonography to detect the presence of TARTs.

Features of TARTs in ultrasonography consisted mostly of multiple ill-defined bilateral masses and hypoechoic and highly vascular lesions near the mediastinum with sizes ranging from $0.2-3 \mathrm{~cm}$ in its largest diameter (mean: $0.718 \mathrm{~cm}$; median: $0.4 \mathrm{~cm}$; and mode: $0.4 \mathrm{~cm}$ ).

Testicular adrenal rest tumor lesions were found to be bilateral in 5/6 patients (83\%), highly vascular in $4 / 6$ patients $(66 \%)$, hypoechoic in $5 / 6$ patients $(83 \%)$, near the mediastinum in $3 / 6$ patients $(50 \%)$, nodular and hyperechoic in $1 / 6$ patient $(16 \%)$, and have ill-defined borders in $2 / 6$ patients (33\%) (Figures $1 \& 2$ ).

The tumor size remained unchanged with no further growth in 3/6 (50\%) patients with TARTs at the annual follow-up. Three patients required another ultrasound in the following year. No patients showed a regression in tumor size, and sonographic details of patients with TART summarized in Table 2.

Additional findings were detected accidentally on the ultrasound in the form of unilateral bright echogenic foci representing microlithiasis in 2 patients, one of whom was diagnosed with TARTs. Another 2 patients with $\mathrm{CAH}$ had a unilateral or bilateral cyst at the head of the epididymis.

Four (80\%) patients diagnosed with TARTs had advanced bone age with maximum bone advancement by 4.8 years. The other $2(20 \%)$ patients had bone age corresponding to their chronological age.

Hormonal assays. All patients with $\mathrm{CAH}$ with TARTs were found to have high ACTH levels before

Table 1 - Characteristic features of patients with testicular adrenal rest tumors (TARTs) including tanner staging, testicular volume, and penile length.

\begin{tabular}{|c|c|c|c|c|c|c|c|c|}
\hline $\begin{array}{l}\text { Patient } \\
\text { number }\end{array}$ & $\begin{array}{c}\text { Age at TART } \\
\text { detection (years) }\end{array}$ & $\begin{array}{l}{ }^{*} \text { Presence of signs } \\
\text { and symptoms }\end{array}$ & Hyperpigmentation & $\begin{array}{c}\text { Palpable } \\
\text { testicular mass }\end{array}$ & $\begin{array}{l}\text { Tanner stage } \\
\text { "testes" }\end{array}$ & $\begin{array}{l}\text { Tanner stage } \\
\text { "pubic hair" }\end{array}$ & $\begin{array}{c}\text { Testicular } \\
\text { volume }(\mathrm{mm})\end{array}$ & $\begin{array}{l}\text { Penile length } \\
(\mathrm{cm})\end{array}$ \\
\hline 1 & 16.6 & yes & Yes & No & IV & $\mathrm{V}$ & R:15 L:15 & 17 \\
\hline 2 & 20 & no & No & Yes, nodular & $\mathrm{V}$ & $\mathrm{V}$ & $\mathrm{R}: 20 \mathrm{~L}: 25$ & 17 \\
\hline 3 & 10.8 & no & No & No & I & I & R:3 L:2.5 & 6 \\
\hline 4 & 15.6 & no & Yes & No & IV & IV & $\mathrm{R}: 20 \mathrm{~L}: 20$ & 9 \\
\hline 5 & 9.4 & no & Yes & No & I & II & R:3 L:3 & 6 \\
\hline 6 & 8.9 & yes & Yes & No & II/III & III & R: $8 \mathrm{~L}: 10$ & 9 \\
\hline
\end{tabular}

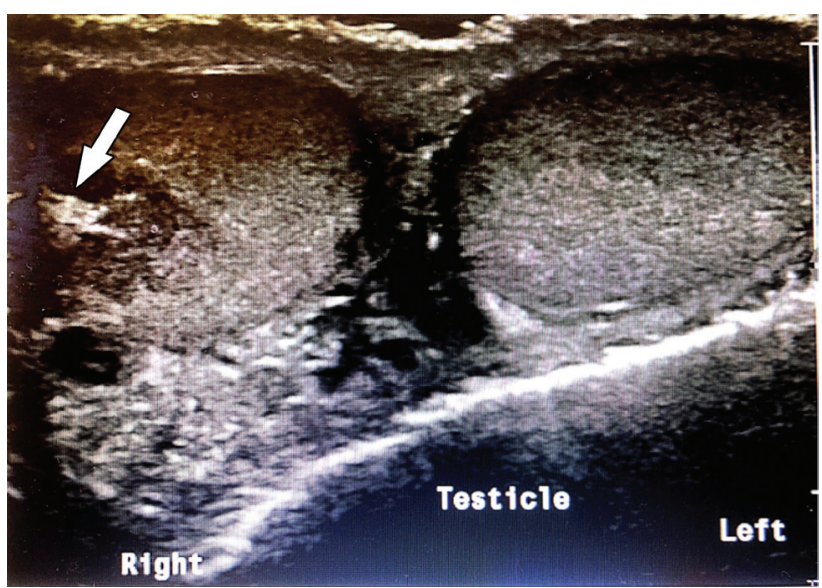

Figure 1 - Bilateral testicular involvement with hypoechoic TART in patient number one.

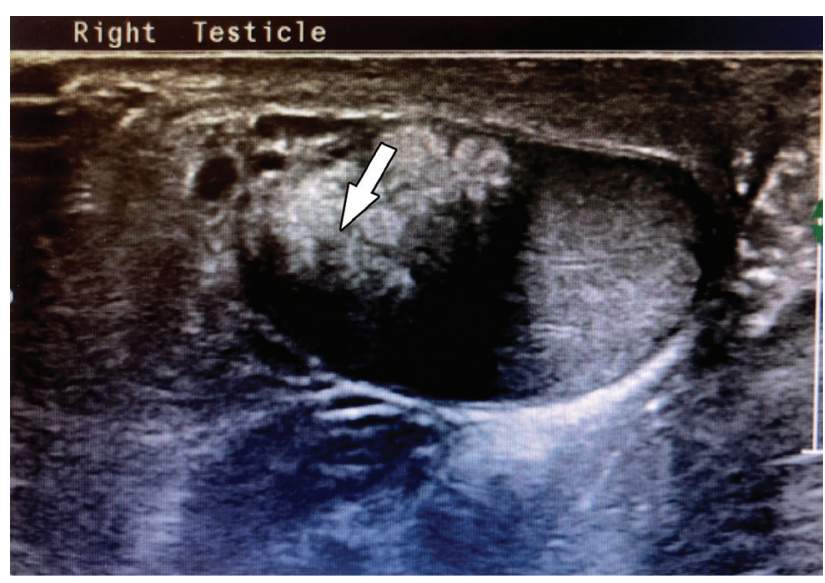

Figure 2 - Hyperechoic testicular adrenal rest tumor (TART) on the right testes of patient number 2 . 
Table 2 - Radiological investigation including sonographic features of testicular ultrasound in patients with congenital adrenal hyperplasia with testicular adrenal rest tumors (TARTs), including bone age advancement.

\begin{tabular}{|c|c|c|c|c|c|c|c|c|}
\hline \multirow[t]{2}{*}{$\begin{array}{l}\text { Patient } \\
\text { number }\end{array}$} & \multicolumn{2}{|c|}{$\begin{array}{l}\text { TART largest diameter on } \\
\text { ultrasonography }(\mathrm{cm})\end{array}$} & \multirow[t]{2}{*}{ Bilateral } & \multirow[t]{2}{*}{ Echogenicity } & \multirow[t]{2}{*}{ Vascular } & \multirow[t]{2}{*}{$\begin{array}{l}\text { Ill-defined } \\
\text { border }\end{array}$} & \multirow[t]{2}{*}{ Site } & \multirow[t]{2}{*}{ Bone age advancement } \\
\hline & $\mathrm{R}$ & $\mathrm{L}$ & & & & & & \\
\hline 1 & \multicolumn{2}{|c|}{ Largest: $0.4 \mathrm{x} 0.4$} & yes & Hypoechoic & increased & yes & - & - \\
\hline 2 & $3 \times 1$ & $1.5 \times 1.3$ & yes & Eccentric hyperechoic & increased & - & - & - \\
\hline 3 & $0.2 \times 0.4$ & $0.3 \times 0.3$ & yes & Hypoechoic & Non-vascular & yes & - & by 1.3 years \\
\hline 4 & $0.4 \times 0.3$ & & no (right) & Hypoechoic & increased & - & mediastinum & by 4.8 years \\
\hline 5 & $0.7 \times 0.6$ & $0.3 \times 0.4$ & yes & Hypoechoic & increased & - & mediastinum & by 3.4 years \\
\hline 6 & \multicolumn{2}{|c|}{ Multiple small } & yes & Hypoechoic & increased & - & mediastinum & by 2.10 years \\
\hline
\end{tabular}

Table 3 - Hormonal assays of patients with congenital adrenal hyperplasia (CAH) with testicular adrenal rest tumor (TARTs).

\begin{tabular}{|c|c|c|c|c|c|c|}
\hline \multirow[t]{2}{*}{ Patient number } & \multicolumn{2}{|c|}{ ACTH $(\mathrm{Pmol} / \mathrm{L})$} & \multirow{2}{*}{$\begin{array}{l}\text { 17-OHP } \\
\text { (ng/mL) }\end{array}$} & \multirow{2}{*}{$\begin{array}{l}\text { DHEA-S } \\
\text { (umol/L) }\end{array}$} & \multirow{2}{*}{$\begin{array}{l}\text { Testosterone } \\
(\mathrm{nmol} / \mathrm{L})\end{array}$} & \multirow{2}{*}{$\underset{(\mathrm{mIU} / \mathrm{L})}{\mathrm{LH}}$} \\
\hline & Prior & After & & & & \\
\hline 1 & 170 & 96 & 1.8 & 0.84 & 34 & 5.68 \\
\hline 2 & 28 & 1.11 & 2.7 & 0.889 & 10.5 & 17.4 \\
\hline 3 & 117 & 9.79 & 0.43 & 0.19 & 0.87 & 0.2 \\
\hline 4 & 80 & 1.96 & 5.9 & 14 & 20.51 & 4.5 \\
\hline 5 & 77 & 1.43 & 3.4 & 0.12 & 0.3 & 1.2 \\
\hline 6 & 105 & 10 & 21.7 & 0.31 & 0.91 & 2.01 \\
\hline
\end{tabular}

tumor detection (3 pubertal and 3 pre-pubertal), most likely due to poor adherence. After TART detection, greater adherence to medication was noticeable as all patients were more educated about the importance of adherence. Adrenocorticotropic hormone levels normalized in 5 affected patients, with only one patient at a pubertal age having a high ACTH level due to incomplete medication adherence. Other hormonal values are presented in Table 3 .

Luteinizing hormone levels in patients with $\mathrm{CAH}$ with TART found to be high in 3 patients (50\%); 2 of them were at pubertal age and one at pre-pubertal age.

Management. All patients with CAH with TARTs were on a glucocorticoid regimen of hydrocortisone $\left(12-18.7 \mathrm{mg} / \mathrm{m}^{2} /\right.$ day divided into 3 doses) and for salt losing type fludrocortisone $(0.1 \mathrm{mg} /$ day as a single dose) was added. In patient number 2 , this regimen was substituted with an equivalent dose of dexamethasone to suppress tumor growth.

Statistical analysis. Backward multiple regression analysis to study factors affecting TART showed that ACTH was an independent factor affecting TART occurrence among patients with CAH (Adjusted
$\mathrm{OR}=1.07$, CI: [1.005-1.142], $p<0.05)$. Further details regarding the comparison of age, BMI, hormonal levels including 17-OHP and DHEA between TART-positive and TART-negative are illustrated in Table 4.

Discussion. In this study, the prevalence of TART in $21 \mathrm{CAH}$ male patients between the age of 4-20 years was $28 \%$ and the youngest child was 8 years old. While TART is a known complication among adolescents and adults with $\mathrm{CAH}$, with a reported prevalence $40 \%$ on average, and up to $94 \% .^{6,18}$ The prevalence in children has been described in various studies, with recent reports of a prevalence of $24 \%$, with 2 cases under the age of 10 years and no cases having a palpable testicular mass. ${ }^{19}$ While a study reported a prevalence of $21 \%$ in male children with CAH and found that TART was detected more in the older boys, there was a similar prevalence of $23.7 \%$ reported with a mean age of 15 years. ${ }^{5,20}$

Testicular adrenal rest tumors were diagnosed in children with $\mathrm{CAH}$ as young as 4-7.5 years, in this study the youngest affected patient was 8 years. ${ }^{3-7}$ Although, TART was not detected in neonates or toddlers, a single study reported the presence of TART in young children 
Table 4 - Comparison between TART negative and positive cases as regard all parameter.

\begin{tabular}{|c|c|c|c|c|c|c|c|c|c|c|}
\hline \multirow[t]{3}{*}{ Parameters } & \multicolumn{8}{|c|}{ TART } & \multirow[t]{3}{*}{$P$-value** } & \multirow[t]{3}{*}{ Sig } \\
\hline & \multicolumn{4}{|c|}{ Negative } & \multicolumn{4}{|c|}{ Positive } & & \\
\hline & Mean \pm SD & Median & \multicolumn{2}{|c|}{ IQR } & Mean \pm SD & Median & \multicolumn{2}{|c|}{$\mathrm{IQR}^{*}$} & & \\
\hline Age & $12.20 \pm 5.16$ & 11.00 & 8.00 & 15.00 & $12.83 \pm 4.62$ & 12.50 & 9.00 & 15.00 & 0.797 & NS \\
\hline BMI & $19.78 \pm 6.14$ & 18.10 & 15.20 & 23.20 & $25.55 \pm 4.55$ & 25.40 & 21.30 & 27.70 & 0.054 & NS \\
\hline ACTH & $18.73 \pm 26.00$ & 9.00 & 2.20 & 21.10 & $96.17 \pm 47.41$ & 92.50 & 77.00 & 117.00 & 0.001 & HS \\
\hline Testosterone & $5.07 \pm 7.27$ & 0.35 & 0.09 & 11.00 & $11.18 \pm 13.70$ & 5.71 & 0.87 & 20.50 & 0.161 & NS \\
\hline DHEA-S & $1.75 \pm 3.81$ & 0.15 & 0.00 & 1.41 & $2.72 \pm 5.53$ & 0.58 & 0.19 & 0.88 & 0.274 & NS \\
\hline 17-OHP & $6.72 \pm 9.01$ & 2.80 & 0.44 & 14.80 & $5.99 \pm 7.91$ & 3.05 & 1.80 & 5.90 & 0.697 & NS \\
\hline $\mathrm{LH}$ & $4.36 \pm 10.37$ & 0.20 & 0.00 & 4.50 & $5.17 \pm 6.34$ & 3.26 & 1.20 & 5.68 & 0.114 & NS \\
\hline $\mathrm{FSH}$ & $12.91 \pm 37.86$ & 0.20 & 0.00 & 3.67 & $5.72 \pm 7.46$ & 3.09 & 0.70 & 6.73 & 0.069 & NS \\
\hline
\end{tabular}

TART: testicular adrenal rest tumor, Sig: significance level, IQR: Interquartile range, BMI: body mass index, ACTH: adrenocorticotropic hormone, DHEA-S: dehydroepiandrosterone, 17-OHP: 17-hydroxy progesterone, LH: luteinizing hormone, FSH: follicle stimulating hormone

with $\mathrm{CAH}$ as the youngest affected patient was 1.8 year old. ${ }^{9,21}$

It was suggested that TART prevalence increases with age, as the nature of the disease would require time to develop. ${ }^{22}$ In a 6-year follow-up study of patients with CAH aged 3-23 years, the prevalence of TARTs increased from $41 \%$ to $66 \%$ in those patients during the follow up, with 16 times greater chance of TART development due to poor control mostly at pubertal age. ${ }^{23}$ Diagnosing TART more frequently at pubertal age in patients with $\mathrm{CAH}$ could be attributed to the rising LH levels at puberty. Additionally, the presence of LH receptors in the testicular tumor tissue suggested that LH may have additional stimulating effects on tumor growth. ${ }^{24}$ This study detected TART in 3 pubertal and 3 pre-pubertal patients with CAH.

Congenital adrenal hyperplasia is a disease inherited in autosomal recessive fashion caused by a genetic mutation, commonly in the CYP21A2 gene, leading to deficiency in enzymes particularly 21-hydroxylase enzyme where it was involved in more than $90 \% .{ }^{25}$ The deficiency or complete absence of those enzyme lead to inadequate cortisol secretion, where the negative feedback to the hypothalamus-pituitary axis is lost. Subsequently, the pituitary gland secretes a high level of ACTH, resulting in hyperplasia of the adrenal gland and increased secretion of adrenal androgens. Chronically high levels of ACTH have been shown to effect on patients with CAH and may play a role in TART development. Additionally, excess androgens cause bone age advancement. In previous reports, advanced bone age was detected in $66-100 \%$ of patients with TARTs. ${ }^{8,26}$ This study demonstrated the presence of advanced bone age in 4 patients with TARTs.
Adrenocorticotropic hormone may play an important role in tumor growth as ACTH receptors were observed in testicular tumor tissues, and $\mathrm{ACTH}$ suppression has been shown to maintain or even reduce the tumor size. ${ }^{27-29}$ On the contrary, patients with TARTs with good hormonal control showed unchanged or even increased tumor size, indicating possible roles of other factors in TART development. ${ }^{30}$ Three patients with TART in this study had unchanged in the tumor size during ultrasonography follow up.

Children diagnosed with TARTs commonly had impalpable mass during the physical examination as the lesions were located in the rete testes and only palpable when $>2 \mathrm{~cm}$ in size. This is likely due to the smaller tumor size in children, which has been reported to range between $2-8 \mathrm{~mm} .{ }^{19}$ This study found a palpable nodular testicular mass in only one patient, with the largest diameter measuring $3 \mathrm{~cm}$ on ultrasonography. The other 5 patients had no palpable masses, and they were only detected by ultrasound (range: $0.2-0.7 \mathrm{~cm}$ in diameter; median size: $0.4 \mathrm{~cm}$ ).

Ultrasonography is a safe, inexpensive, and fast modality for TART detection. It detects lesions as small as $2 \mathrm{~mm}$. However, very small lesions observed in stage one cannot be detected by ultrasound, and in stage 2 they appear as hypoechoic lesions. Hyperechogenic lesions represent fibrosis of the mass starting in stage $3 .{ }^{11}$ Testicular adrenal rest tumor sonographic features mostly consisted of bilateral lesions near the mediastinum that are hypoechoic with copious blood supply. ${ }^{26}$

In this study, ultrasonographic screening was conducted for all patients with $\mathrm{CAH}$ above the age of 4 years, as recommended in previous studies, to screen 
children with CAH for TARTs. ${ }^{8}$ Testicular adrenal rest tumor was detected in 6 patients with findings of ill-defined borders in 2 patients, high vascularity in 4 patients, hypo-echoic lesions in 5 patients, and a hyperechoic mass in one patient. The TART was located near the mediastinum in 3 patients.

The presence of bilateral testicular involvement is indicative of TARTs in patients with CAH, as TART has been reported as a bilateral disease in most studies $(80 \%){ }^{8}$ Although, some studies reported bilateral involvement in only $14 \%$ of patients with CAH. ${ }^{31}$ Testicular adrenal rest tumor was observed to have bilateral involvement in 5 patients $(83 \%)$ in this study. Interestingly, additional findings were detected during testicular ultrasonography screening. In patients with CAH with TARTs, ultrasound detected the presence of microlithiasis in $28 \%$ of patients. ${ }^{32}$ Similarly, microlithiasis was observed in patients with $\mathrm{CAH}$ without TARTs. $^{33}$ In this study, microlithiasis was observed in 2 patients with $\mathrm{CAH}$, one of whom was diagnosed with TART. Moreover, 2 patients with $\mathrm{CAH}$ were found to have epididymal head cysts. The chronic tumor had an unwanted effect on the testicular parenchyma, with inflammation, fibrosis, and a large tumor obstructing the seminiferous tubules adversely affecting gonadal function and fertility. ${ }^{11}$ Treatment of TARTs consists mainly of incremental glucocorticoid dosage adjustments to shrink or maintain tumor size, while others reported an increase in tumor size while on treatment. ${ }^{28-30}$ Prescribing an equivalent dose of dexamethasone has shown some benefits, TARTs are known to have benign features; however, surgical resection may be required to preserve testicular function or fertility and for Stage 4 or 5 lesions or large painful discomforting lesions that are refractory to medical therapy. ${ }^{33}$ In this study, glucocorticoid were administered to all patients with CAH. Patients with TARTs that did not respond to the usual dose were prescribed a higher dose or had the dose substituted with an equivalent dexamethasone dose.

Study limitations. It was difficult to compensate for the missing data of some non-eligible patients with $\mathrm{CAH}$, whom travelled abroad permanently as they were not reachable.

In conclusion, the importance of TART screening in children with $\mathrm{CAH}$ has been increasing worldwide. Most detected cases were found to have impalpable masses with poor hormonal control. Annual screening of children with $\mathrm{CAH}$ using testicular ultrasonography for early detection and management is highly recommended.
Acknowledgment. The authors gratefully acknowledge Editage for English language editing.

\section{References}

1. Speiser PW, Arlt W, Auchus RJ, Baskin LS, Conway GS, Merke DP, et al. Congenital adrenal hyperplasia due to steroid 21hydroxylase deficiency: an endocrine society clinical practice guideline. J Clin Endocrinol Metab 2018; 103: 4043-4088.

2. Al-Jurayyan NA, Al-Herbish AS, Abo Bakr AM, Al-Rabeeah AA, Al-Samarrai AI, Jawad AJ, et al. Congenital adrenal hyperplasia in a referral hospital in Saudi Arabia: epidemiology, pattern and clinical presentation. Ann Saudi Med 1995; 15: 447-450.

3. Aycan Z, Bas VN, Cetinkaya S, Yilmaz Agladioglu S, Tiryaki T. Prevalence and long-term follow-up outcomes of testicular adrenal rest tumours in children and adolescent males with congenital adrenal hyperplasia. Clin Endocrinol (Oxf) 2013; 78: 667-672.

4. Ma L, Xia Y, Wang L, Liu R, Huang X, Ye T, et al. Sonographic features of the testicular adrenal rests tumors in patients with congenital adrenal hyperplasia: a single-center experience and literature review. Orphanet J Rare Dis 2019; 14: 242.

5. Mendes-Dos-Santos CT, Martins DL, Guerra-Júnior G, Baptista MTM, de-Mello MP, de Oliveira LC, et al. Prevalence of testicular adrenal rest tumor and factors associated with its development in congenital adrenal hyperplasia. Horm Res Paediatr 2018; 90: 161-168.

6. Kocova M, Janevska V, Anastasovska V. Testicular adrenal rest tumors in boys with 21-hydroxylase deficiency, timely diagnosis and follow-up. Endocr Connect 2018; 7: 544-552.

7. Mouritsen A, Jørgensen N, Main KM, Schwartz M, Juul A. Testicular adrenal rest tumours in boys, adolescents and adult men with congenital adrenal hyperplasia may be associated with the CYP21A2 mutation. Int J Androl 2010; 33: 521-527.

8. Kim MS, Goodarzian F, Keenan MF, Geffner ME, Koppin CM, De Filippo RE, et al. Testicular adrenal rest tumors in boys and young adults with congenital adrenal hyperplasia. J Urol 2017; 197: 931-936.

9. Dumic M, Duspara V, Grubic Z, Oguic SK, Skrabic V, Kusec V. Testicular adrenal rest tumors in congenital adrenal hyperplasiacross-sectional study of 51 Croatian male patients. Eur J Pediatr 2017; 176: 1393-1404.

10. Stikkelbroeck NM, Otten BJ, Pasic A, Jager GJ, Sweep CG, Noordam K, et al. High prevalence of testicular adrenal rest tumors, impaired spermatogenesis, and Leydig cell failure in adolescent and adult males with congenital adrenal hyperplasia. J Clin Endocrinol Metab 2001; 86: 5721-5728.

11. Claahsen-van der Grinten HL, Hermus AR, Otten BJ. Testicular adrenal rest tumours in congenital adrenal hyperplasia. Int J Pediatr Endocrinol 2009; 2009: 624823.

12. Nuttall FQ. Body mass index: obesity, BMI, and health: a critical review. Nutr Today 2015; $50: 117-128$.

13. Wang YN, Zeng Q, Xiong F, Zeng Y. Male external genitalia growth curves and charts for children and adolescents aged 0 to 17 years in Chongqing, China. Asian J Androl 2018; 20: 567-571.

14. Marshall WA, Tanner JM. Variations in the pattern of pubertal changes in boys. Arch Dis Child 1970; 45: 13-23.

15. Emmanuel M, Bokor BR. Tanner stages. Treasure Island (FL): StatPearls Publishing; 2021. 
16. Iannaccone G. W. W. Greulich and S. I. Pyle: radiographic atlas of skeletal development of the hand and wrist. 2nd edition. I volume-atlante di 256 pagine. Stanford university press, Stanford, California, 1959. Acta Geneticae Medicae Et Gemellologiae 1959; 8: 513-513.

17. Park E, Cho M, Ki CS. Correct use of repeated measures analysis of variance. Korean J Lab Med 2009; 29: 1-9.

18. Engels M, Span PN, van Herwaarden AE, Sweep FCGJ, Stikkelbroeck NMML, et al. Testicular adrenal rest tumors: current insights on prevalence, characteristics, origin, and treatment. Endocr Rev 2019; 40: 973-987.

19. Claahsen-van der Grinten HL, Sweep FC, Blickman JG, Hermus AR, Otten BJ. Prevalence of testicular adrenal rest tumours in male children with congenital adrenal hyperplasia due to 21-hydroxylase deficiency. Eur J Endocrinol 2007; 157: 339-344.

20. Martinez-Aguayo A, Rocha A, Rojas N, García C, Parra R, Lagos M, et al. Testicular adrenal rest tumors and Leydig and Sertoli cell function in boys with classical congenital adrenal hyperplasia. J Clin Endocrinol Metab 2007; 92: 4583-4589.

21. Kim MS, Koppin CM, Mohan P, Goodarzian F, Ross HM, Geffner ME, et al. Absence of testicular adrenal rest tumors in newborns, infants, and toddlers with classical congenital adrenal hyperplasia. Horm Res Paediatr 2019; 92: 157-161.

22. Claahsen-van der Grinten HL, Dehzad F, Kamphuis-van Ulzen $\mathrm{K}$, de Korte CL. Increased prevalence of testicular adrenal rest tumours during adolescence in congenital adrenal hyperplasia. Horm Res Paediatr 2014; 82: 238-244.

23. Werneck G, Rodrigues EMR, Mantovani RM, Lane JSS, Silva IN. Testicular adrenal rest tumors in patients with congenital adrenal hyperplasia: 6 years of follow-up. J Pediatr Endocrinol Metab 2019; 32: 519-526.

24. Benvenga S, Smedile G, Lo Giudice F, Trimarchi F. Testicular adrenal rests: evidence for luteinizing hormone receptors and for distinct types of testicular nodules differing for their autonomization. Eur J Endocrinol 1999; 141: 231-237.
25. El-Maouche D, Arlt W, Merke DP. Congenital adrenal hyperplasia. Lancet 2017; 390: 2194-2210.

26. Wang Z, Yang Z, Wang W, Chen LD, Huang Y, Li W, et al. Diagnosis of testicular adrenal rest tumors on ultrasound: a retrospective study of 15 cases report. Medicine (Baltimore) 2015; 94: e1471.

27. Claahsen-van der Grinten HL, Otten BJ, Sweep FC, Span PN, Ross HA, Meuleman EJ, et al. Testicular tumors in patients with congenital adrenal hyperplasia due to 21-hydroxylase deficiency show functional features of adrenocortical tissue. $J$ Clin Endocrinol Metab 2007; 92: 3674-3680.

28. Giacaglia LR, Mendonca BB, Madureira G, Melo KF, Suslik CA, Arnhold IJ, et al. Adrenal nodules in patients with congenital adrenal hyperplasia due to 21-hydroxylase deficiency: regression after adequate hormonal control. J Pediatr Endocrinol Metab 2001; 14: 415-419.

29. Jin HY, Choi JH, Kim GH, Lee CS, Yoo HW. Testicular adrenal rest tumors in a patient with untreated congenital adrenal hyperplasia. Korean J Pediatr 2011; 54: 137-140.

30. Stikkelbroeck NM, Hermus AR, Suliman HM, Jager GJ, Otten BJ. Asymptomatic testicular adrenal rest tumours in adolescent and adult males with congenital adrenal hyperplasia: basal and follow-up investigation after 2.6 years. J Pediatr Endocrinol Metab 2004; 17: 645-653.

31. Çakir ED, Mutlu FS, Eren E, Paşa AO, Sağlam H, Tarim O. Testicular adrenal rest tumors in patients with congenital adrenal hyperplasia. J Clin Res Pediatr Endocrinol 2012; 4 : 94-100.

32. Poyrazoglu S, Saka N, Agayev A, Yekeler E. Prevalence of testicular microlithiasis in males with congenital adrenal hyperplasia and its association with testicular adrenal rest tumors. Horm Res Paediatr 2010; 73: 443-448.

33. Claahsen-van der Grinten HL, Otten BJ, Sweep FC, Hermus AR. Repeated successful induction of fertility after replacing hydrocortisone with dexamethasone in a patient with congenital adrenal hyperplasia and testicular adrenal rest tumors. Fertil Steril 2007; 88: 705. 